\title{
De cárceles y concesiones: Privatización carcelaria y penalidad neoliberal
}

\author{
Isabel Arriagada Gajewski*
}

\begin{abstract}
RESUMEN
Este trabajo realiza un recorrido por los orígenes de las políticas de privatización penitenciaria de mediados de los ochenta, vinculadas a la explosión carcelaria de fines del siglo XX y al despliegue punitivo de los gobiernos neoliberales asentados tras la crisis del Estado de bienestar. Tras ello, se abordan brevemente distintas experiencias privatizadoras comparadas, para luego referir a la experiencia de concesiones carcelarias chilena. El propósito tras este análisis es introducir una lectura crítica de la privatización carcelaria y entregar un aporte que contribuya a la prosecución del debate y a la ulterior valoración de las políticas y prácticas penales en la actualidad.
\end{abstract}

Privatización carcelaria - concesiones carcelarias - derecho penitenciario

\section{Prisons and concessions: The privatization of prisons and neoliberal punishment}

\begin{abstract}
This paper gives an account of the origins of prison privatization policies of the mid-eighties, linked to the rapid expansion of prisons in the late twentieth century and the punitive deployment by neoliberal governments after the crisis of the welfare state. It briefly considers and compares different experiences of privatization, then focuses on the Chilean experience of prison concessions. The purpose behind this analysis is to introduce a critical reading of prison privatization and give impetus to further discussion and assessment of current penal policies and practices.
\end{abstract}

Prison privatization - prison concessions - Prison Law

* Abogada, Investigadora del Centro de Estudios de la Justicia, Universidad de Chile, Pío Nono 1. Edificio Santa María. Oficina 508, Santiago de Chile. Correo electrónico:isabelarriagada@gmail.com Artículo recibido el 30 de marzo de 2012 y aceptado para su publicación por el Comité Editorial el 26 de octubre de 2012. 


\section{EL SURGIMIENTO DE LA PRISIÓN PRIVADA}

\section{Orígenes $y$ antecedentes}

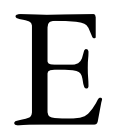
1 origen de la privatización carcelaria se remonta, según indica la literatura norteamericana, a la década de los ochenta ${ }^{1}$. Pese a existir antecedentes que dan cuenta de la participación de intereses privados en el sistema carcelario en épocas previas, ellos no se corresponden con la morfología actual del panorama de la privatización. Entre los referentes anteriores están las casas de corrección (workhouses) surgidas en el siglo XVI en el Reino Unido; el trabajo de los carceleros de los Estados Unidos colonial, encargados de poner a disposición del Estado a los prisioneros, cobrando sus honorarios de acuerdo con una tarifa prefijada; los servicios prestados por empresarios del transporte para labores de deportación; y el derecho de carcelaje consignado por los presos a sus carceleros por concepto de estadía y alimentación. Está también la explotación mediante trabajos forzados de la mano de obra de los reclusos, masificada en la década de 1870 luego de la crisis de la guerra civil norteamericana, abandonada tras las críticas de abuso a los internos y la oposición de sindicatos e industrias de trabajadores libres que veían en las prisiones una competencia desleal ${ }^{2}$. Asimismo, pese a la continua absorción de la función punitiva por el Estado durante los siglos XIX y XX, las empresas privadas participaban proveyendo servicios a las cárceles públicas ${ }^{3}$, siendo las iglesias y la filantropía privada las encargadas de asistir y colaborar con las necesidades de los presos del siglo XIX ${ }^{4}$.

La diferencia entre aquellas manifestaciones y la privatización actual vendría dada por la circunstancia de que la prisión privada hoy es una actividad de origen contractual, regulada exhaustivamente, financiada directa o indirectamente por el Estado, administrada bajo estándares de control prefijados y sujeta, en mayor o menor medida,

${ }^{1}$ Véase Dolovich S., "State punishment and private prisons". en Duke Law Journal, Vol. $55 \mathrm{~N}^{\circ} 3$. 2005, pp. 437-546. Loï Wacquant, Castigar a los pobres: El gobierno neoliberal de la inseguridad social, Gedisa, Barcelona, 2010. Bernard Harcourt, The Illusion of Free Markets: Punishment and the Myth of Natural Order, Harvard University Press, Cambridge, 2011. Pratt T. y Maahs J., "Are Private Prisons More Cost-Effective Than Public Prisons? A Meta-Analysis of Evaluation Research”, en Crime and delinquency, Vol. $45 \mathrm{~N}^{\circ} 3$. 1999, pp. 358-372.

${ }^{2}$ Dolovich, op. cit., n. 1, pp. 450-451, Wacquant, op. cit., n. 1, p. 247. Ruiz-Jarabo, D. "Prisiones privadas", en Jueces para la democracia. Información y Debate, Vol. 8. 1989, p. 42. Sobre él léase system en Estados Unidos, White, A. "Rule of law and the limits of sovereignty: the private prison in jurisprudential perspective", en The American Criminal Law Review, Vol. 38 N $^{\circ}$ 1. 2001, pp. 129-130. Según Foucault, "al exigir el sistema industrial un mercado libre de mano de obra, la parte del trabajo obligatorio hubo de disminuir en el siglo XIX en los mecanismos de castigo, sustituida por una detención con fines correctivos”, Foucault, M. Vigilar y Castigar: el Nacimiento de la prisión, Siglo Veintiuno Editores, Madrid, 2000, p. 32.

${ }^{3}$ Schichor, D. "Private prisons in perspective: some conceptual issues", en The Howard Journal, Vol. 37 $\mathrm{N}^{\circ} 1.1998$, p. 82.

${ }^{4}$ Garland, D. La cultura del control. Crimen y orden social en la sociedad contemporánea, Gedisa, Barcelona, 2005, p. 88. 
a responsabilidades 5 . Siguiendo a Enrique Sanz, la prisión privada sería entonces una unidad penal cuya dirección y administración se encuentra a cargo de una entidad privada, permaneciendo bajo la responsabilidad del sector público en un régimen contractual con el Estado ${ }^{6}$. Además, y en cuanto al contexto en que se desarrolla, la introducción actual del capital privado en el área penitenciaria tiene lugar en un medio en el que coexisten, entre otras características, una ciega predilección por la cárcel como medio de castigo y un bestial incremento de la población penal ${ }^{7}$. A este respecto se ha sostenido que la configuración actual del fenómeno ${ }^{8}$ habría irrumpido en Estados Unidos luego del explosivo aumento del encarcelamiento a partir de la década de los setenta, en el que "[d]e menos de 380.000 en 1975, la población carcelaria llegó a 500.000 reclusos en 1980, antes de saltar a más de un millón en 1990"9 , generándose un incremento de casi $400 \%$ desde inicios de los 80 hasta el año 2002, período en que la población reclusa estadounidense ascendía a 1,4 millones de personas ${ }^{10}$.

Existe un amplio debate acerca de las razones por las cuales el sistema penal norteamericano aumentó vertiginosamente sus tasas de encarcelamiento. David Garland sostiene que la superficie social y económica de la "modernidad tardía" ${ }^{11}$ habría desatado distintas circunstancias favorecedoras de la actividad delictiva, entre ellas, el aumento

${ }^{5}$ Dolovich, op. cit., n. 1, p. 454.

${ }^{6}$ Sanz, E. Las prisiones privadas: la participación privada en la ejecución penitenciaria. Edisofer, Madrid, 2000, pp. 141-143.

${ }^{7}$ Según Robert Weiss, en Estados Unidos, desde 1973 en adelante, el explosivo aumento de las tasas de encarcelación puso término a un período de tasas estatales y federales estables de aproximadamente 110 presos por cada 100.000 habitantes. Weiss, R. "Repatriating Low-Wage Work: The Political Economy of Prison Labor Reprivatization in the Postindustrial United States”, en Criminology, Vol. 39 N $^{\circ}$ 2. 2001, p. 263.

${ }^{8}$ Como da cuenta Enrique Sanz, la terminología para referirse al "fenómeno" ha sido un punto difícil de zanjar. Sanz, E. op. cit., n. 6. 2000, pp. 141-143. En particular, también se vuelve difícil usar la expresión "prisiones" privadas para referirse a la situación en Estados Unidos cuando en este país existen diferencias entre prisons (prisiones) y jails (cárceles). Solo por razones metodológicas, en el desarrollo de este trabajo ambos términos se utilizan indistintamente. Por lo demás, la diferencia entre ambos tipos de establecimientos radica en que las primera están destinadas a los responsables de infracciones castigadas con penas superiores a un año de privación de libertad (felonies) y las gestionan, bien el gobierno federal, bien los gobiernos estatales, mientras que las segundas se reservan para los responsables de infracciones castigadas con penas inferiores a un año de privación de libertad (misdemeanors), infracciones menores (petty offences) o para presos preventivos. Las cárceles las gestionan las autoridades del condado, por medio de la oficina del Sheriff, o las autoridades municipales, mediante el correspondiente departamento de policía. Del Rosal, B. 'La 'privatización' de las prisiones: una huida hacia la pena de privación de libertad”, en Eguzkilore: Cuaderno del Instituto Vasco de Criminología $\mathrm{N}^{\circ} 12$. 1998. Nota al pie $\mathrm{N}^{\circ} 30$.

9 Wacquant, op. cit., n. 1, p. 180. Con más exactitud, algunos fijan la fecha de inicio del proceso expansivo en 1973, año en el cual se habría iniciado el desarrollo del complejo de prisión industrial bajo las políticas del gobernador de Nueva York, Nelson Rockefeller. Harcourt, op. cit., n. 1, p. 236.

${ }^{10}$ Aman Jr., A. "Privatization, prisons, democracy, and human rights: The need to extend the province

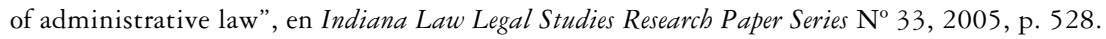

${ }^{11}$ Entendiendo por ella a una compleja constelación de circunstancias económicas, políticas y culturales, como son el estado actual de la producción capitalista y el intercambio de mercado, el desarrollo de la tecnología, el transporte y las telecomunicaciones, las variaciones en la configuración de las familias, las mutaciones sufridas por las ciudades y la democratización de la vida social y cultural. Garland, op. cit., n. 4. Passim. 
de las oportunidades para cometer delitos, la disminución de los controles situacionales, el incremento de la población en riesgo y la reducción de la eficacia del control social $^{12}$. En la vereda opuesta, Loïc Wacquant ha sostenido no existir un correlato entre el aumento de las tasas de encarcelación y el aumento de la comisión de delitos, sino que aquel sería producto de un modelo de control social discriminatorio y excluyente. Bajo esta visión, la explicación del aumento de las tasas de encarcelamiento tendría su origen, entonces, no en el aumento de la criminalidad, sino en el de la criminalización ${ }^{13}$, debido sobre todo por la intensificación del castigo respecto de delitos no violentos, el tráfico de drogas, infracciones a condiciones impuestas en el medio libre y conductas reincidentes ${ }^{14}$. Apoya a esta postura el hecho de que las tasas delictuales a la época en que se iniciaron los procesos de encarcelación masiva, habrían no solo logrado estabilizarse sino que, incluso, disminuir ${ }^{15}$.

Con todo, ante el explosivo aumento de las tasas de encarcelamiento, las autoridades se vieron obligadas a resolver el problema de la disponibilidad de plazas para los cada vez más numerosos presos ${ }^{16}$. Alineadas con el programa político de la era Reagan, se dio paso a la tendencia de privatizar los servicios tradicionalmente proveídos por el sector público, propiciando así la decisión de liberalizar la gestión carcelaria. De este modo, las autoridades estatales acuden al sector privado con la expectativa de contar con un aliado flexible y creativo, capaz de generar rentabilidad con la gestión penitenciaria mediante una operación más eficiente, de mayor calidad y a un menor costo que el de las agencias gubernamentales ${ }^{17}$.

Aun cuando se indica que a fines de los setenta el United States Immigration and Naturalization Service (INS) habría sido el organismo pionero en la experiencia privatizadora $^{18}$, el notorio ascenso de la privatización de las prisiones aparece cuando la primera

${ }^{12}$ Garland, op. cit., n. 4, p. 160.

${ }^{13}$ Schlosser, E. The Prison-Industrial Complex, [En línea] Atlantic Monthly, 1998. Disponible en web http://www.theatlantic.com/magazine/archive/1998/12/the-prison-industrial-complex/4669 [Visitado por última vez el 29 de marzo de 2012].

${ }^{14}$ Algunas de estas causas se encuentran señaladas en Western, B. "The impact of incarceration on wage mobility and inequality", en American Sociological Review, Vol. 67, agosto 2002, p. 527.

${ }^{15}$ Wacquant, op. cit., n. 1, p. 193.

16 Las autoridades no solo se vieron enfrentadas a una sobrepoblación penitenciaria que ocupaba instalaciones deterioradas y escasas, sino también a cortes de justicia que ordenaban reformas por un tratamiento digno de los presos, a presupuestos estatales reducidos y a la recesión económica originada por la crisis del petróleo, a sentencias condenatorias, al endurecimiento de la opinión pública frente al delito, a la "guerra contra las drogas", a la resistencia de los contribuyentes a asumir los costos de construir nuevas prisiones y a una multiplicidad de factores que contribuían a la asfixiante tensión del problema. Charles Logan, Private Prisons. Cons E Pros, Oxford University Press, New York, 1990, p. 9. También sobre las circunstancias que habrían motivado la política de privatización penitenciaria en Estados Unidos, Dana, J. “A Guide to Prison Privatization”, en Heritage Foundation Backgrounder, Washington, 1988. Disponible en http://www.heritage.org/research/reports/1988/05/bg650-a-guide-to-prison-privatization [Visitado por última vez el 24 de marzo de 2012].

${ }^{17}$ Schichor, op. cit., n. 3, p. 82.

${ }^{18}$ El INS contrató servicios privados de detención de inmigrantes ilegales con audiencias de deportación pendientes. McDonald, D. "Public Imprisonment by private means: The re-emergence of private prisons and 
entidad privada, Corrections Corporation of America (en adelante, CCA), fundada en Nashville en 1983, se adjudicara extensos contratos con los estados de Texas y Tennessee ${ }^{19}$. La CCA, como exhibe la página web de la compañía, fue creada para responder a la idea de crear asociaciones público-privadas con el fin de sustituir los defectos en la gestión del gobierno y proporcionar decisiones más inteligentes y eficaces para el futuro ${ }^{20}$. En 1988 existían al menos 20 instituciones privadas operando en nueve estados a nivel federal, estatal y local ${ }^{21}$, y un intenso debate público sobre los argumentos para incentivar o detener su crecimiento ${ }^{22}$. Ya para el año 2008, el $8 \%$ de los presos de Estados Unidos estaba recluido en una prisión privada ${ }^{23}$. Actualmente las compañías privadas en Estados Unidos dedicadas al "negocio de la prisión" traspasan los márgenes de la gestión carcelaria, llegando incluso a formar parte de la economía nacional. Por ejemplo, la CCA en Estados Unidos no solo absorbe la demanda por la encarcelación y los servicios ligados a ella, sino que también proporciona empleos a cerca de 17.000 profesionales dedicados a la seguridad, la academia, la educación vocacional, servicios de salud, programas para presos, mantenimiento, recursos humanos, gestión y administración ${ }^{24}$. Además, sobre su presencia en el mercado bursátil, la CCA participa desde 1994 en la bolsa de Nueva York y sus acciones han aumentado de forma sorprendente ${ }^{25}$, de manera que la compañía se ha capitalizado en 3,5 billones de dólares, convirtiéndose en una apuesta casi segura para los inversionistas ${ }^{26}$. Finalmente, cruzando incluso las fronteras estadounidenses, las dos principales compañías de la industria correccional americana, CCA y Wackenhut, hoy denominada GEO Group, participan actualmente de los mercados carcelarios de otros gobiernos neoliberales anglosajones, como Australia, Inglaterra, Escocia, y en países como Sudáfrica y Nueva Zelanda.

En cuanto a las formas que han ido adoptando los contratos con las empresas del sector privado en Estados Unidos, ellas son diversas y su contenido varía de acuerdo con los servicios y actividades encomendadas a la gestión privada ${ }^{27}$. En un intento por

jails in the United Stated, the United Kingdom and Australia”, en British Journal of Criminology, Vol. 34 No 29. 1994, p. 30. En todo caso, cuál habría sido la primera cárcel privada propiamente tal es una cuestión a la que se han dado distintas respuestas. Así por ejemplo, hay quienes consideran ser el Weaversville Intensive Treatment Unit, fundado en 1976 en Pennsylvania. Aman op. cit., n. 10, p. 527.

19 Dana, op. cit., n. 16, pp. 4-5.

${ }^{20}$ Información disponible en http://www.cca.com/about/cca-history/. [Visitado por última vez el 24 de marzo de 2012].

${ }^{21}$ Harcourt, op. cit., n. 1, p. 235.

${ }^{22}$ McDonald, op. cit., n. 18, p. 31.

${ }^{23}$ Harcourt, op. cit., n. 1, p. 235.

${ }^{24} \mathrm{La}$ información se encuentra disponible en http://www.cca.com/about/. [Última visita realizada el día 24 de marzo de 2012].

${ }^{25}$ Harcourt, op. cit., n. 1, p. 236.

26 Parenti, C. Lockdown America: Police and Prisons in the Age of Crisis, Editorial Verso, New York, 2000, p. 219.

${ }^{27}$ Entre la diversidad de catálogos explicativos sobre las distintas configuraciones de la privatización carcelaria, existe una exhaustiva tipología elaborada por Austin y Coventry. Disponible en Austin, J. y Coventry, G. "Emerging Issues on Privatized Prisons” U.S Department of Justice, 2001, p. 69. 
clasificarlas, puede sostenerse que las fórmulas de participación privada concebidas en Estados Unidos y extendidas bajo distintas modalidades en otros países se resumen en tres modelos ${ }^{28}$ : El modelo de leasing, en virtud del cual las empresas privadas, con capitales propios o aportados, diseñan, construyen e implementan el recinto penitenciario para luego traspasarlo al Estado cuando este haya pagado por dichas prestaciones en el plazo convenido; el modelo de privatización, que delega absolutamente la actividad penitenciaria en el sector privado, encargándose el Estado de su fiscalización; y el modelo mixto, que delega algunas actividades al sector privado, encargándose el Estado de cumplir las funciones de seguridad y vigilancia de los reclusos al interior del establecimiento.

\section{Penalidad neoliberal}

A estas alturas, la construcción de cárceles privadas en Estados Unidos aparece como una medida que concuerda con el recorrido que va desde el compromiso social con el delincuente, propio del Estado de bienestar y de la ingeniería social de posguerra, hacia la reconfiguración de un complejo penal propio de las políticas económicas neoliberales. Valga al respecto una breve síntesis. Hasta 1970 al menos, el sistema penal en Estados Unidos afirmaba un compromiso solidario con el delincuente afianzado en una trama coherente de principios enmarcados en un sistema penal estatal, legitimado y reflexivo, caracterizado por la restricción en el uso del encarcelamiento, la preponderancia de medidas de custodia, la confianza en el profesional técnico experto y el protagonismo del ideal de rehabilitación. La ideología de la penalidad en el Estado de bienestar se asentaba en la convicción de que la prosperidad económica conducía a la reducción del delito y, por tanto, de que la responsabilidad de castigar y controlar a los delincuentes era una misión del Estado, el cual debía darse a la tarea de buscar las causas de la criminalidad en la pobreza o en los déficit de socialización de la población penal, generados por una sociedad capitalista e industrializada. Según David Garland, luego del welfarismo penal y a partir de los años setenta, se inicia un convulsivo período de transformación de las prácticas y los discursos en torno a la penalidad, el cual, sustentado en la necesidad de defender los derechos de los presos, reveló la retórica paternalista y aparentemente benigna del welfarismo que no hacía si no un uso discriminatorio del poder de castigar, amparando en él a pervertidas políticas de rehabilitación, condenas indeterminadas, tratamientos individualizados y medidas moralizantes. Desafortunadamente, a este sano proceso crítico sucedería una imprevista e histérica reconfiguración de la agenda punitiva, fundada en distintas bases que encaminaron el endurecimiento del sistema penal; a saber, el incremento de la severidad de las penas, la irrupción de la justicia expresiva, los cambios en el tono emocional de un discurso político populista -hoy conocido como populismo punitivo-, la presencia de medios de comunicación sensacionalistas y aferrados al

\footnotetext{
${ }^{28}$ Arellano Quintana, J. "Reforma Penitenciaria: El caso del programa de concesiones en infraestructura penitenciaria en Chile”. En: Seminario Justicia y Gobernabilidad Democrática del Centro de Estudios de Justicia de las Américas y Ministerio de Justicia de Chile, 2003, Santiago de Chile, p. 6. Disponible en http://www.cejamericas.org/portal/index.php/es/biblioteca/biblioteca-virtual/doc_details/2097-reformapenitenciaria-el-caso-del-programa-de-concesiones-en-infraestructura-penitenciaria-en-chile [Última visita realizada el 24 de mazo de 2012].
} 
fenómeno del miedo al delito, la visión del delincuente como un sujeto antisocial, egoísta, peligroso y autorresponsable ${ }^{29}$, el énfasis en la protección de la víctima y, finalmente, un uso masivo e indiscriminado de la prisión como medio de incapacitación ${ }^{30}$. Así entonces, el renovado interés por la prisión, y la intervención de capitales privados en ella, es una deriva que armoniza, por un lado, con el abandono de la responsabilidad social del Estado y, por otro, con el advenimiento del despliegue del poder punitivo que ha acompañado a los gobiernos neoliberales; caracterizados por su permanente hesitación sobre la capacidad estatal de promover el bienestar social ${ }^{31}$.

En todo caso, cuáles sean las verdaderas y efectivas funciones del mercado y del Estado en los gobiernos neoliberales, tanto en el desarrollo social como en la esfera punitiva, es una pregunta a la que se han ofrecido distintas respuestas. La versión más difundida del pensamiento neoliberal lo describe como uno que decide entregar el bienestar económico y social al libre desarrollo de las capacidades personales de los individuos, relegando al Estado a la función de regular el marco institucional en que ellas se despliegan y a dar garantía de la correcta operatividad de los mercados, función que incorpora, entre otras actividades, "disponer las funciones y estructuras militares, defensivas, policiales y legales que son necesarias para asegurar los derechos de propiedad privada y garantizar, en caso necesario mediante el uso de la fuerza, el correcto funcionamiento de los mercados" 32 . En suma, un Estado ajeno a la distribución de recursos y reducido a su rol de agente regulador, objetivo e imparcial. Sin embargo, análisis más suspicaces del rol del Estado en la política neoliberal, y en particular, de su relación con el campo punitivo, consideran que el encogimiento del Estado social y la fortaleza del Estado penal son dimensiones interdependientes. De modo que el mercado, facilitador de la liberalización del capital, precarizador de las protecciones sociales y motor de la marginalidad avanzada, "halla su extensión ideológica y su complemento institucional en la 'mano de hierro' del Estado penal, que crece y se despliega a fin de contener los desórdenes generados por la difusión de la inseguridad social" 33 (cursivas en el original). Así entendido, los resultados a que han dado lugar las políticas neoliberales permiten aseverar que simplemente no existe el binomio libre mercado/regulación estatal, sino que solo habría una ilusión de neutralidad que esconde un complejo e intrincado proceso de distribución de riqueza establecido legalmente, y frente al cual habría que avocarse a la tarea de determinar a quién y cuánto favorece, y de evaluar, política y normativamente, la justicia (si es que la hay) detrás de esos resultados distributivos ${ }^{34}$.

\footnotetext{
${ }^{29}$ En particular, sobre la relación entre los discursos políticos de la época y la autorresponsabilidad del delincuente, véase Wacquant, op. cit., n. 1.

${ }^{30}$ Por todos, Garland op. cit., n. 4.

${ }^{31}$ Sobre el cuestionamiento neoliberal al Estado de Bienestar, Garland, op. cit., n. 4, p. 134.

${ }^{32}$ Harvey, D. Breve historia del neoliberalismo, Ediciones Akal, Madrid, 2007, p. 6. Sobre los orígenes del término y de sus posibles significados dentro del liberalismo, Ghersi, E. "El mito del neoliberalismo". en Estudios Públicos No 95. 2004.

33 Wacquant, op. cit., n. 1, p. 35.

${ }^{34} \mathrm{Al}$ respecto, Bernard Harcourt refiere: "La idea de un mercado autorregulado es absurda. Sería como una competencia deportiva sin un árbitro: No funcionaría ni ha funcionado nunca. Una vez que vemos las
} 
En lo que a este trabajo interesa, cabe afirmar que la agenda económica y política de la era Reagan aparece como fiel reflejo de esta versión del neoliberalismo. Su programa incluyó, por un lado, el impulso a la libertad de mercado y la puesta en marcha de la privatización estatal y, por otro, la reducción de la protección social y el confinamiento de la legitimidad y competencia del Estado a la esfera penal, operando como condición de posibilidad del desarrollo carcelario y del giro punitivo que tuvo lugar desde la década de los setenta ${ }^{35}$. En este proceso, la prisión se convirtió un componente político e institucional del Estado, y cuya consolidación es producto de la penalización de la miseria provocada por la inseguridad social de los gobiernos neoliberales, convirtiéndose en una especie de contención penal del nuevo y precarizado proletariado urbano $^{36}$. Para ello los privados son sindicados como un valioso aliado: si el Estado busca expandir extensiva e intensivamente el campo penal, entonces la avidez de los privados por participar y desarrollar este nuevo mercado proporciona una herramienta que fortalece al poder de castigar, asiste a los propósitos expansivos y consolida la actual vocación penal de los estados neoliberales.

\section{Una idea de exportación}

La privatización de las cárceles fue una idea que pronto se propagó, expandiéndose a países de los distintos continentes y adaptándose a las más variadas realidades nacionales. La reproducción de esta idea se inscribe en el marco general de exportación de la constelación de creencias sobre la penalidad impulsadas desde Estados Unidos y que marcaron la reducción del Estado social y el fortalecimiento del Estado penal en varios países europeos

reglas del juego quedaría igualmente en claro que dichas reglas y reglamentos distribuyen recursos. La altura de la canasta de básquetbol favorece a la gente alta”. Traducción personal. Texto original en inglés: The idea of a self-regulated market is preposterous. It would be like a competitive sporting event without a referee: it would not work, nor has it ever worked. And once we see the rules of the game it becomes equally clear that those rules and regulations distribute resources. The height of the basketball hoop favors tall people. Harcourt, op. cit., n. 1, p. 196. El fenómeno ha sido también descrito como "capitalismo regulatorio" o "capitalismo regulado", entendiendo por tal a un "orden político, económico y social donde la regulación es la parte en expansión del gobierno, más que la provisión directa de servicios privados o públicos”. Traducción personal. Texto original en ingles: Regulatory capitalism is a political, economic and social order where regulation, rather than the direct provision of public and private services, is the expanding part of government. John Braithwaite, Regulatory Capitalism: How it Works, Ideas for Making it work Better. Edward Elgar Publishing, London, 2008, p. viii. Según Braithwaite, la denominación "capitalismo regulatorio" es preferible a la de "Estado regulador", ya que la expansión regulatoria es un fenómeno común al sector público y al sector privado. Como dato adicional, y a diferencia de las tesis de Harcourt, Wacquant, Harvey y Garland, Braithwaite sostiene que el auge de la regulación no es un correlato del neoliberalismo (cuyo derrumbe, por lo demás habría tenido lugar tras la crisis asiática de 1997), ya que la regulación tanto podría favorecer las libertades negativas de los individuos como sus libertades positivas.

${ }^{35}$ El discurso político da cuenta de aquello, tanto directamente, por haber iniciado el uso a la penalidad dentro de una retórica electoral que combinó el ensalzamiento del libre mercado con el endurecimiento penal, como indirectamente, debido a que con ello se naturalizó convincentemente la guerra contra el delito y redujo la resistencia y el debate público frente a ella. Harcourt, op. cit.,n. 1, pp. 202-208.

${ }^{36}$ Wacquant, L. “El cuerpo, el gueto y el Estado penal”. En Apuntes de investigación No 16/17, 2010, p. 110. 
y latinoamericanos ${ }^{37}$. La infinidad de conexiones entrelazadas entre los Estados Unidos emisor y los numerosos países receptores requerirían de un trabajo intenso y exhaustivo que excede la tarea que en este examen se desarrolla. No obstante, al menos de manera resumida, abordaré algunas de las experiencias vinculadas a la ya referida tendencia estadounidense ${ }^{38}$.

En el Reino Unido, tal como en Estados Unidos, existieron antecedentes de privatización constituidos por los convenios celebrados entre el Ministerio del Interior y compañías privadas para contratar servicios de detención de inmigrantes ${ }^{39}$. Coinciden también, ambos países, en que sus procesos de privatización fueron liderados por gobiernos neoliberales y conservadores, como lo fueron los gobiernos de Ronald Reagan y George Bush (19811992) y el de la primera ministra Margaret Tatcher (1979-1991). Al respecto, pese a su extensión, la cita a David Garland resulta ineludible: "A lo largo de la década de 1980 y durante gran parte de la década de 1990, la Nueva Derecha dominó la política social y económica en Estados Unidos y Gran Bretaña. Revirtiendo las soluciones solidarias del Estado de bienestar, con su preocupación por la igualdad social, la seguridad social y la justicia social, la nueva política neoliberal insistía en el fundamentalismo de mercado y la fe incuestionable en el valor de la competencia, la empresa y los incentivos, así como también en los efectos saludables de la desigualdad y la exposición al riesgo. Con esta finalidad, los gobiernos de ambos países impulsaron la aprobación de leyes para controlar a los sindicatos, reducir los costos laborales, desregular las finanzas, privatizar el sector público, extender la competencia de mercado y reducir los beneficios del welfare" ${ }^{40}$.

Ahora bien, pese a las similitudes de ambos procesos, las propuestas de privatización carcelaria en Gran Bretaña fueron en alguna medida independientes al desarrollo que vivió Estados Unidos en los años ochenta. Se ha sostenido que mientras en Estados Unidos el impulso por la privatización provino más bien de la pretensión lucrativa de los empresarios privados, en Gran Bretaña procedía de propuestas originadas en el debate político y académico (desde el Adam Smith Institute ${ }^{41}$, por ejemplo) ${ }^{42}$. Además, mientras en Estados Unidos la decisión privatizadora provenía de cada estado en particular,

37 Wacquant, L., Las cárceles de la miseria, Ediciones Manantial, Buenos Aires, 2000, pp. 21-22. Wacquant analiza la constitución e internacionalización del nuevo campo punitivo por medio del examen de distintas agencias estatales y think tank neoconservadores, a quienes considera protagonistas de la expansión.

${ }^{38}$ Sobre la experiencia de privatización en Europa, cabe considerar que los países de la Unión Europea ven limitada su regulación por los límites que impone la Unión en sus normas penitenciarias.

${ }^{39}$ McDonald, op. cit., n. 18, p. 32.

${ }^{40}$ Garland, op. cit., n. 4, p. 172.

${ }^{41}$ En un informe de 1984 elaborado por el Adam Smith Institute sobre política criminal, se declaraba: "La sobreocupación carcelaria y las celdas compartidas son productos inherentes a un sistema influido por las consideraciones políticas y sometido a fuerzas políticas que permiten que se resienta la inversión de capital y reducen la flexibilidad para cambiar (...). Cualquier solución realista probablemente implica una mayor capitalización, una más eficaz utilización del potencial humano, una más amplia utilización de las innovaciones tecnológicas y nuevas alternativas a la prisión, quizá basadas precisamente en los avances tecnológicos (...). Todo esto es difícil que se produzca en un contexto como el presente, con un sistema de preferente gestión política, por lo que cualquier solución radical aparece como más atractiva”. Adam Smith Institute: Omega Report. Justice Policy, Londres, 1984, p. 52. En: Del Rosal, op. cit., n. 8, p. 130.

${ }^{42}$ McDonald, op. cit., n. 18, pp. 29-30. Según McDonald, en este caso la influencia no sería unidireccional, sino que habría una especie de fertilización cruzada (cross-fertilization) entre ambos países. 
generando movimientos locales de privatización, en Gran Bretaña la política fue implementada desde el gobierno central, lo que generó un proceso privatizador con mayor uniformidad. Con todo, pese a la independencia del fenómeno, el desarrollo posterior del proceso de privatización carcelaria en el Reino Unido es atribuible en parte a la influencia norteamericana. Ello, porque el Comité de Asuntos Internos (Home Affaire Committee) de la Cámara de los Comunes, entidad encargada de la superintendencia parlamentaria del sistema carcelario, realizó un viaje a algunas prisiones privadas estadounidenses en el marco de una investigación sobre el estado de las cárceles en Inglaterra y Gales. El reporte elaborado luego de la visita recomendó al Ministerio del Interior británico permitir la participación de compañías privadas en licitaciones para la construcción y gestión de instituciones de custodia, fundamentalmente de centros de detención preventivos, ya que en ellos existía la mayor concentración de sobrepoblación penal ${ }^{43}$. En 1989, tras la iniciativa del gobierno británico para elaborar un documento de trabajo sobre el tema (Green Paper), distintos asesores privados realizaron sus indicaciones. La consultoría destacó los beneficios que conllevaría la participación de privados en el sistema carcelario, sugiriendo su intervención tanto en la construcción y manejo de las cárceles como en el aprovisionamiento del personal y escoltas en cárceles y tribunales. Pronto el gobierno británico decidió contratar a empresas privadas para la construcción de la Worlds Remand Prison, una nueva cárcel en North Humberside ${ }^{44}$. Para ello se dictó la Criminal Justice Act de $1991^{45}$, la que permitió la participación de privados en centros de reclusión preventivos para imputados no condenados. Poco tiempo después, la autorización contenida en la referida norma se expandió a la construcción y operación de cárceles para todo tipo de presos. En 1992 el gobierno contrató al UK Detention Services, un consorcio entre la CCA norteamericana y firmas de construcción británicas, para construir una prisión en Blakenhurst, tanto para reclusos condenados como sujetos a prisión preventiva. Ya en 1997 empezó a operar HMP Altercourse, la primera prisión diseñada, construida, gestionada y financiada íntegramente por una compañía privada. Actualmente, de acuerdo con el Her Majesty’s Prison Service, existen 11 prisiones manejadas por compañías privadas ${ }^{46}$.

En España los antecedentes remotos de la participación de privados en el sector penitenciario se remiten a la utilización de los condenados en la formación de las filas de los ejércitos españoles, ahorrando al Estado tanto los costos de formación del ejército como el pago por el encarcelamiento de los reclusos ${ }^{47}$, y a la asistencia prestada por instituciones religiosas en la administración de centros de reclusión en los siglos XIX

43 Íd., p. 33.

${ }^{44}$ La construcción tuvo lugar no obstante que a inicios de los noventa la población penal disminuyera, reduciendo consigo la necesidad de construir nuevas cárceles. Gill Lf, "Private sector involvement in the Prison System of England and Wales”. Inédito (1992). En McDonald, op. cit., n. 18, p. 34.

$45 \mathrm{El}$ contenido del acta se encuentra disponible en http://www.legislation.gov.uk/ukpga/1991/53/ contents [Visitado por última vez el 29 de marzo de 2012].

46 Información disponible en http://www.justice.gov.uk/about/hmps [Visitado por última vez el 29 de marzo de 2012].

${ }^{47}$ Del Rosal, op. cit., n. 8, pp. 116-117. 
y $\mathrm{XX}^{48}$. Tal como fuera sostenido anteriormente, este tipo de intervenciones se aleja de las condiciones que permiten verificar la presencia del fenómeno de la prisión privada contemporánea, por lo que cabe avocarse a los antecedentes recientes que configuran el panorama actual de la institucionalidad carcelaria española. A lo largo de la década de los ochenta existió en España un considerable aumento de la población reclusa, lo que provocó el desbordamiento de centros y establecimientos penitenciarios. Frente a aquello, en 1991 se elaboró el "Plan de Creación y Amortización de Centros Penitenciarios". Dicho programa contempló la clausura de las instalaciones carcelarias ubicadas en los centros de las ciudades, la venta de dichos terrenos y la construcción, a cuenta de los ingresos generados, de 14 recintos penitenciarios en las afueras de las ciudades ${ }^{49}$. El año 2005, tras la revisión y actualización del mencionado plan, el Consejo de Ministros en España autorizó la construcción de " 46 nuevas infraestructuras penitenciarias en el período 20062012, con una inversión de 1.647,20 millones de euros que se suman a otros 1.504,20 millones ya aprobados por anteriores Consejos de Ministros" ${ }^{50}$, habida consideración de que la construcción de dichos centros constituía una necesidad urgente. La trayectoria punitiva de la agenda penitenciaria española se encuentra a la vista. En cuanto a la presencia de agentes privados, cabe destacar que su intervención se ve enfrentada a la Constitución de 1978, la que consagra la exclusiva competencia del Estado en la legislación penitenciaria (Artículo 149.1.6a) y a la Ley Orgánica General Penitenciaria, que entrega el núcleo de la actividad a la Dirección General de Instituciones Penitenciarias (art. 79 LOGP 1/1979), de manera que el recurso a las compañías privadas inicialmente se consideró impensable ${ }^{51}$. No obstante la reserva constitucional y el mandato legal referidos, y aun cuando la prudencia del sistema español no permita hablar en rigor de privatización, existe una evolución hacia el favorecimiento de las posibilidades de actuación de colaboradores no estatales ${ }^{52}$. Así, por ejemplo, existen talleres productivos cuya gestión, de acuerdo con los artículos 138 y siguiente del Reglamento Penitenciario, puede encargarse tanto al Organismo Autónomo de Trabajo y Formación para el Empleo (OATPFE) como a la colaboración de empresarios privados ${ }^{53}$; así también, en materia de responsabilidad penal de menores, se permite la participación de instituciones privadas

${ }^{48}$ Ibid.

${ }^{49}$ Íd., p. 122. Nota al pie $\mathrm{N}^{\circ} 19$.

${ }^{50}$ Ministerio del Interior España, “Interior invertirá más de 1.647 millones de euros en la construcción de 46 nuevas infraestructuras penitenciarias”. 18 de noviembre de 2005. Disponible en http://www.mir.es/ press/interior-invertira-mas-de-1-647-millones-de-euros-en-la-construccion-de-46-nuevas-infraestructuraspenitenciarias-4017? locale=es [Última visita realizada el 29 de marzo de 2012].

${ }^{51}$ Ruiz-Jarabo, op. cit., n. 2, p. 44.

52 Sanz, E. "Los límites de la participación privada en el ámbito penitenciario", Anuario de Derecho Penal y Ciencias Penales 52 (1-3), 1999, p. 386.

53 Institución Penitenciaria, "El sistema penitenciario español”. [En línea], Madrid, Secretaría general de instituciones penitenciarias, 2011, p. 37. Disponible en http:/www.institucionpenitenciaria.es/web/ export/sites/default/datos/descargables/publicaciones/Sistema_Penitenciario_Espanol_2011.pdf [Visitado por última vez el 25 de mazo de 2012]. 
para la ejecución de las medidas adoptadas por los Jueces de Menores ${ }^{54}$; asimismo, son empresas privadas a quienes se ha encargado la fase de construcción de los establecimientos ${ }^{55}$; y el Reglamento Penitenciario español en su artículo 300 también permite que sean empresas externas, adjudicatarias por contrato administrativo de servicios, las que presten los servicios de economato, cocina y cafetería del recinto. Aun cuando estas intervenciones puedan ser consideradas discretas, y a pesar de que parecen distar en su mayoría del ánimo de lucro que ha guiado el desarrollo de la industria privada de la prisión, nada impide que sean evaluadas bajo el mismo lente con el que ha de juzgarse al fenómeno en su totalidad.

En Francia, pese a que la saturación de los recintos carcelarios ha sido menor que en otros países europeos ${ }^{56}$, ha tenido lugar una igualmente intensa preocupación por el sistema carcelario y las posibilidades de privatizarlo. El legislador galo ha adoptado un régimen doble. Existen "las denominadas instituciones clásicas, que son aquellas que perviven aún de la gestión centralizada, y existen, también, aquellas otras que permanecen bajo el mismo formato de gestión pero en calidad de experimento control" 57 (cursivas en el original). Este segundo tipo de instalación es consecuencia del contrato entre el gobierno y empresas privadas, tengan o no fines de lucro, bajo el cual el gobierno se encarga de mantener y controlar a los reclusos, mientras que a las empresas privadas se les confían las labores de diseño, construcción y equipamiento de instalaciones penitenciarias. Adicionalmente, se permite la subcontratación de todos los servicios que sean entregados en las prisiones, como alimentación, vestuario e higiene, exceptuando las tareas de dirección, secretariado y seguridad ${ }^{58}$. Con ello se habría dado paso a un modelo de gestión mixta público-privado o de semiprivatización "en el cual se externalizan la construcción, explotación y gestión de los recintos, dejándose en manos del estado sus tareas inherentes de vigilar y castigar" 59 , razón por la cual puede afirmarse que no existen en Francia cárceles privadas propiamente tales. La ventaja de este sistema, se ha

${ }^{54}$ Sanz, op. cit., n. 52, p. 387.

55 Por ejemplo, Infraestructuras y Equipamientos Penitenciarios S.A. participa activamente en procesos de construcción y adquisición de terrenos, levantamientos topográficos y realización de estudios geométricos. $I d$, p. 390.

56 Al año 2006 la población reclusa en Francia ocupaba las instalaciones penales al $115 \%$ de su capacidad. Información disponible en: Centro de Estudios Jurídicos y Formación Especializada. “¿Políticas del castigo? Análisis comparativo del discurso de política penitenciaria en: Dinamarca, Francia, Inglaterra, Gales y Canadá”, Generalitat de Catalunya. Departamento de Justicia, Barcelona, 2009, p. 50. Disponible en http://www20.gencat.cat/docs/Justicia/Documents/ARXIUS/SC-1-075-09_cas.pdf [Visitado por última vez el 25 de marzo de 2012].

${ }^{5}$ Íd., p. 60. Así también, Ruiz-Járabo. op. cit., n. 2, pp. 41-42.

58 Ruiz-Jarabo, op. cit., n. 2, p. 41-42. Véase también Williamson, B. "Los modelos de administración de centros privativos de libertad”. En: Fundación Paz Ciudadana, Estudio sobre Modelos de Intervención y Administración de Centros Privativos de Libertad en la Reforma Penal Adolescente. Informe Final [En línea], Santiago, Ministerio de Justicia, 2009, p. 37-44. Disponible en http://web.minjusticia.cl/dosvias/doc/Informe\% 20 Final\%20Completo.pdf [Última visita realizada el día 25 de marzo de 2012].

59 Antonio Frey, "Seguridad ciudadana, ambivalencia de las políticas criminológicas y privatización del sistema carcelario" [En línea], en Revista de la Academia, Vol. 5, 2000, p. 31. Disponible en http://www. 
sostenido, es que lograría aliviar al Estado de aquellas actividades conexas a la gestión penitenciaria para entregarlas a un operador capacitado, especializado y flexible, permitiendo la dedicación estatal exclusivamente a las actividades que le son propias: la vigilancia y la reinserción de los imputados. La consolidación de este modelo tuvo lugar en la década de los noventa y, ya para el año 2007 "existían 27 establecimientos bajo el modelo mixto público privado, los cuales albergaban el $25 \%$ del total de la población penitenciaria del país" 60 .

En el contexto regional, algunos países como Venezuela, México, Perú, Brasil y Chile han abordado, algunos con mayor o menor ímpetu, la posibilidad de participación del sector privado en el sistema penitenciario. De ellos cabe hacer al menos una sinopsis de sus más importantes características y particularidades.

En Venezuela, la Constitución de 1999 dio lugar a la autorización expresa de delegar el ejercicio de la función penitenciaria en agentes privados. En su artículo 272 se establece que los establecimientos penitenciarios "se regirán por una administración descentralizada, a cargo de los gobiernos estatales o municipales, pudiendo ser sometidos a modalidades de privatización”. La idea de la intervención de agentes privados en el sistema penitenciario se habría enmarcado en el esfuerzo por reducir los elevados niveles de hacinamiento y violencia en los establecimientos carcelarios del país ${ }^{61}$. No obstante esta consagración, la privatización penitenciaria en Venezuela ha vivido un tímido, si es que no ausente, proceso de implementación.

En México la situación de las cárceles adolece de similares deficiencias. El Informe Especial sobre la situación de los Derechos Humanos en los Centros de Reclusión de la República Mexicana elaborado por la Comisión Nacional de Derechos Humanos retrata, entre otros, problemas de sobrepoblación, hacinamiento, corrupción, desnutrición, insuficiencia de personal y ausencia de servicios médicos ${ }^{62}$. Según da cuenta Faviola Tapia en su libro Hacia la privatización de las prisiones el antecedente de las iniciativas de intervención privada en México se remonta a la investigación que habría realizado un equipo de funcionarios mexicanos el año 2000, en que, al amparo de la Organización de Estados Americanos, concluyó en la conveniencia de construir cuatro establecimientos penitenciarios con capital privado en las provincias de Tenancingo, Tenango del Valle, Ixtlahuaca y Zumpango ${ }^{63}$. Sin embargo, “y con total hermetismo, el gobierno estatal canceló la participación de la iniciativa privada en la construcción de las cuatro

academia.cl/biblioteca/publicaciones/Academia_05/Seguridadciudadanaambivalenciadelaspoliticas.pdf [Última visita realizada el 25 de marzo de 2012].

${ }^{60}$ Williamson, op. cit., n. 58, p. 39.

61 Resulta particularmente ejemplificadora la resolución de la Corte Interamericana de Derechos Humanos sobre las obligaciones de adoptar medidas provisionales impuestas al gobierno venezolano. Disponible en http://www.corteidh.or.cr/docs/medidas/vistahermosa_se_01.pdf [Visitado por última vez el 25 de marzo de 2012].

62 Informe disponible en http://www.cndh.org.mx/node/35 [Visitado por última vez el 25 de marzo de 2012].

63 Tapia, F. Hacia la Privatización de las Prisiones, Editorial Ubijus, México DF, 2011, p. 87. 
cárceles" 64 . Luego de dicha experiencia, una de las más recientes propuestas que se han dado para responder a la preocupante situación carcelaria mexicana fue la del Partido Verde Ecologista de México para apoyar "la intervención del sector privado en la construcción, operación y administración de los centros penitenciarios dependientes de la federación, con la correspondiente rectoría del Estado"65. Por el momento, la iniciativa del proyecto de decreto de la Ley Federal del Sistema Penitenciario y de Ejecución de Sanciones se encuentra aprobada, dándose lugar a su tramitación ${ }^{66}$, incluyéndose en ella la participación del sector privado en el otorgamiento de empleo a los reclusos ${ }^{67}$, aunque, al parecer, sin haberse concretado el acuerdo por una mayor intervención. Sobre la situación particular del Distrito Federal (DF) en México, el mayor desarrollo de la participación privada estaría teniendo lugar en el ámbito de la industria penitenciaria mediante convenios de colaboración ${ }^{68}$. Algunos de los problemas que habrían surgido tras la implementación de estos convenios estarían la escasa capacitación que recibe la población reclusa y las deudas que el empresariado mantiene con la institución ${ }^{69}$. Similar intervención ha tenido lugar en Perú ${ }^{70}$, país que, para enfrentar el hacinamiento de la población reclusa, mediante su Agencia de Promoción de la Inversión Privada (PROINVERSIÓN), desde el año 2001 permite la intervención del sector privado en los establecimientos penitenciarios (Resolución Suprema No 291-2001-EF) ${ }^{71}$.

En Brasil la cruda realidad carcelaria ${ }^{72}$ llevó a las autoridades, en el año 2011, a decidir implantar un sistema de complejos carcelarios en el estado de Minas Gerais (Ribeirão das Neves) y en Pernambuco (Centro Integrado de Resocialización de Itaquitinga) operados en su integridad por agentes privados. Aunque ya existían cárceles concesionadas en

${ }^{64}{ }^{I} d .$, p. 89.

65 Diario de los Debates de la Cámara de Diputados. Sesión del 23 de noviembre de 2010, p. 233 Disponible en http://cronica.diputados.gob.mx/PDF/61/2010/nov/101123-2.pdf [Visitado por última vez el 25 de marzo de 2012].

${ }^{66} \mathrm{Su}$ articulado se encuentra disponible en la página de la presidencia mexicana. http://www.presidencia. gob.mx/iniciativas-de-ley/iniciativa-con-proyecto-de-decreto-por-el-que-se-expide-la-ley-federal-del-sistemapenitenciario-y-de-ejecucion-de-sanciones-y-se-reforma-la-ley-organica-del-poder-judicial-de-la-federacion/ [Última visita realizada el 25 de marzo de 2012].

${ }^{67}$ Artículo 94 VII la Ley Federal del Sistema Penitenciario y de Ejecución de Sanciones

68 Una escueta especificación de las labores penitenciarias proporcionada por la Subsecretaría de Sistema Penitenciario mexicana se encuentra disponible en http://www.reclusorios.df.gob.mx/subsecretaria/ trabajo_penitenciario/trabajo_penitenciario.html [Visitado por última vez el 29 de marzo de 2012].

69 Tapia, op. cit., n. 63, p. 91.

${ }^{70}$ Sobre la situación carcelaria en Perú. COMISIÓN EPISCOPAL DE ACCIÓN SOCIAL. Perú: Informe sobre la situación penitenciaria. Lima, CEAS, 2005. Disponible en http://perso.unifr.ch/derechopenal/assets/ files/obrasportales/op_20080612_18.pdf [Última visitada realizada el 29 de marzo de 2012].

${ }^{71}$ La culminación del proceso de privatización carcelaria en Perú se llevó a cabo cuando PROINVERSIÓN, el año 2011 y luego de haber elaborado la versión final del contrato de concesión, cuyas bases fueran aprobadas el año 2010, ofertó a la empresa privada el otorgamiento de la concesión plena de un centro penitenciario en la región de Lima respecto de las labores de diseño, financiamiento, construcción, operación y mantenimiento.

${ }^{72}$ Un breve resumen sobre la realidad carcelaria brasileña retratada en HUMAN RIGHTS WATCH. World Report 2011. Events of 2010. [En línea] USA, Human Rights Watch, 2010. Disponible en http://www. hrw.org/en/world-report-2011 [Última visita realizada el 29 de marzo de 2012 
Brasil, establecidas mediante la modalidad de "parcerías (asociaciones) público privadas" (PPP) del sistema brasileño ${ }^{73}$, estas serán las primeras cuya seguridad y vigilancia estén a cargo de particulares, situación que las convierte en las primeras cárceles íntegramente privadas en Latinoamérica ${ }^{74}$.

\section{El CASO CHILENO}

En 1996 debutó en Chile la Ley de Concesiones de Obras ${ }^{75}$ (en adelante, Ley de Concesiones), marco normativo que, junto a su respectivo Reglamento ${ }^{76}$, amparó una nueva forma de relación contractual con el sector privado, construida sobre la base de una asociación pública-privada de largo plazo que transfiere la inversión, construcción y explotación de servicios públicos, en las condiciones definidas en la legislación y en cada contrato de concesión ${ }^{77}$, consagrando así un sistema de tipo BOT (Built, Operate and Transfer), bajo el cual el sector privado, contando al parecer con la capacidad técnica, humana y tecnológica para ello, construye y opera una obra pública para luego transferirla al Estado. En virtud de este marco, el año 2000 el Ministerio de Justicia facultó $^{78}$ al Ministerio de Obras Públicas para iniciar el proceso de licitación de las obras comprendidas en el primer "Programa de Concesiones de Infraestructura Penitenciaria". Adecuándose al modelo mixto desarrollado bajo la experiencia francesa, el programa

73 Sobre la estructura y atribuciones de las asociaciones público privadas: en Brasil http://www.ppp. mg.gov.br/unidadeppp [Visitado por última vez el 29 de marzo de 2012].

${ }^{74} \mathrm{La}$ información se encuentra disponible en Sminc, V. "Brasil tendrá las primeras cárceles privadas en América Latina” [En línea] BBC Mundo Cono Sur. Domingo, 19 de junio de 2011, http://www.bbc. co.uk/mundo/noticias/2011/06/110616_brasil_carcel_privada_vs.shtml [Visitado por última vez el 29 de marzo de 2012].

${ }^{75}$ Decreto Supremo MOP N ${ }^{\circ}$ 900, del 31 de octubre de 1996, que fijó el Texto Refundido, Coordinado y Sistematizado del Decreto con Fuerza de Ley MOP No 164 de 1991 y modificada el año 2010 por la Ley $\mathrm{N}^{\circ} 20.410$ del 20 de enero de 2010.

${ }^{76}$ Reglamento No 164 de 1991 modificado por las Leyes No 19.252 de 1993 y No 19.460 de 1996.

${ }^{77}$ Figueroa, J. E. "El arbitraje en los contratos de concesión de obras públicas en Chile. Incorporación de los Dispute Boards o Paneles Técnicos o de Expertos”. [En línea] Gaceta Jurídica No 350, 2009, p. 2. Disponible en http://www.camsantiago.cl/articulos_online_3.htm [Visitado por última vez el 27 de marzo de 2012].

${ }^{78}$ El artículo 39 inciso segundo del Decreto 900: "El Ministerio de Obras Públicas es competente para otorgar en concesión toda obra pública, salvo el caso en que tales obras estén entregadas a la competencia de otro Ministerio, servicio público, Municipio o empresa pública u otro organismo integrante de la administración del Estado. En estos casos, dichos entes públicos podrán delegar mediante convenio de mandato suscrito con el Ministerio de Obras Públicas, la entrega en concesión de tales obras bajo su competencia, para que éste entregue su concesión, regida por esta ley. En estos casos se entenderá incluido en dicho convenio la totalidad del estatuto jurídico de concesiones de obras públicas, esto es, tanto el procedimiento de licitación, adjudicación y la ejecución, conservación y explotación como las facultades, derechos y obligaciones que emanan de la ley". En cuanto a las atribuciones pertinentes del Ministerio de Justicia: Artículo 2 Ley Orgánica Constitucional del Ministerio de Justicia, DL 3346 de 22 de mayo de 1980 letras c), d) y 1). Por su parte, la ejecución misma de la pena privativa de libertad se reglamenta por el Decreto Supremo No 518 de 1998. 
contempló que el diseño, construcción, equipamiento y operación de distintas cárceles, clasificadas por grupos según etapas de desarrollo, se adjudicaran a una sociedad concesionaria, permaneciendo la dirección y seguridad del establecimiento a cargo de Gendarmería de Chile ${ }^{79}$. De acuerdo con la estructura contractual implementada, la empresa concesionaria adjudicataria (generalmente un consorcio empresarial integrado por empresas de rubros como construcción, alimentación y aseo) encarga la explotación de la concesión a una empresa operadora, la cual incorpora dentro de sus actividades el mantenimiento de la infraestructura y del equipamiento estándar, labores de seguridad y la prestación de servicios de alimentación, salud, lavandería, reinserción y economato ${ }^{80}$.

El denominado "Grupo 1" incluyó la construcción, ejecución, conservación y explotación de establecimientos penitenciarios en Iquique, La Serena y Rancagua. El año 2002 se adjudicó el contrato a las sociedades Besalco, Astaldi S.A.y Sodexho ${ }^{81}$, asociadas bajo el consorcio BAS S.A. y operadores mediante la empresa SIGES. Para ello se otorgó un presupuesto oficial aproximado de 2.800.000 UF $\mathrm{UF}^{82}$. El año 2006, tras sucesivos conflictos referidos a los sobrecostos de las obras no contempladas inicialmente y luego de haberse condenado al MOP a efectuar pagos adicionales a la concesionaria, el "Grupo 1" inició sus operaciones de manera definitiva. El "Grupo 2" contempló las tareas de construcción, equipamiento y operación de dos instalaciones, ubicadas en las ciudades de Antofagasta y Concepción. La concesión fue adjudicada el año 2002 a las empresas Besalco S.A., Torno Internazionale S.p.A. y Sodexho Chile S.A. ${ }^{83}$, constituida como sociedad concesionaria BAS DOS S.A. y el presupuesto inicial ascendió a la suma de 1.800.000 UF. Luego de sucesivas controversias por sobrecostos entre el MOP y la concesionaria, el contrato de concesión fue extinguido de mutuo acuerdo por las partes. Ya en el año 2010 y luego de un tortuoso proceso de relicitación, ahora bajo la modalidad OT (operate and transfer) ${ }^{84}$, se adjudicó la operación de las cárceles a la empresa Sodexho

${ }^{79} \mathrm{La}$ competencia de dichos ámbitos se encuentra radicada en Gendarmería en virtud del artículo tercero de su Ley Orgánica Constitucional, DL N 2859 de 15 de septiembre de 1979, el cual le otorga la función de dirigir todos los establecimientos penales del país, aplicando las normas previstas en el régimen penitenciario que señala la ley y velar por la seguridad interior de ellos, así como custodiar y atender a las personas privadas de libertad.

${ }^{80}$ Martínez, F. y Espinoza, O. “Cárceles concesionadas en Chile: ¿El camino a la privatización?”, en Debates Penitenciarios, $\mathrm{N}^{\circ}$ 9, 2009, p. 5.

${ }^{81}$ Decreto $\mathrm{N}^{\circ} 618$ del MOP de 28 de marzo de 2002.

${ }^{82}$ Cabe advertir que el monto del presupuesto inicial aquí referido debe considerarse, al menos a efectos de este trabajo, como un dato meramente ilustrativo. Para contar con mayor precisión en el cálculo de los montos desembolsados por el Ministerio de Justicia, debiesen sumarse a dicho monto, y esto vale para todos los grupos carcelarios, el pago del impuesto al valor agregado, el pago por subsidio fijo a la contratación, el pago por subsidio fijo a la operación, el pago subsidio operación variable y pagos adicionales. Sin embargo, basten estos datos para ilustrar el contraste, que aquí se pretende exponer, entre el presupuesto inicial y los pagos por sobrecostos. Sobre este punto, Vid. Infra p. 67 y siguientes.

${ }^{83}$ Decreto No 2191 del MOP de 06 de marzo de 2003 (Derogado).

${ }^{84}$ Frei, J. "Seminario regional. Sistema penitenciario concesionado: desafíos y realidades regionales". Rancagua, Gobierno de Chile-Ministerio de Justicia, 2009. Disponible en http://www.concesiones.cl/ 
Chile S.A ${ }^{85}$. Finalmente, la operación del “Grupo 3", integrado por los complejos penitenciarios Santiago Uno, Valdivia y Puerto Montt, fue adjudicada ${ }^{86}$ a la sociedad Vinci Construction Grand Proyects, operando mediante la empresa COMPASS, y el presupuesto oficial contempló un monto de 2.750.000 UF, posteriormente modificado mediante el recurso a los denominados convenios complementarios. La puesta en marcha definitiva de las obras tuvo lugar el año 2004.

Aunque la limitada extensión de este trabajo impide profundizar al respecto, es deber ineludible realizar un comentario sobre las reiteradas irregularidades del proceso y desarrollo de las concesiones carcelarias en Chile. Al igual que en la experiencia comparada, las autoridades en Chile contaron con que la mayor creatividad e innovación del sector privado, su eficiencia y la libre competencia en la provisión de un servicio público generarían cuantiosos beneficios para el aparato carcelario. Sin embargo, esas expectativas se vieron defraudadas por los innumerables problemas de implementación, en su mayoría atribuibles a una estructura contractual expuesta a los intereses del sector privado. Entre ellos, los excesivos sobrecostos, un cuestionado mecanismo compositivo de comisiones arbitrales, las falencias en la implementación de infraestructura, la precariedad de los servicios proveídos a los internos, la desprotección de las empresas subcontratadas, la inoperante fiscalización y los exorbitantes costos diarios por preso pagados por el Estado. Producto de estas irregularidades, el año 2008 fue constituida una Comisión Especial Investigadora en la Cámara de Diputados con el objeto de estudiar el proceso de concesiones carcelarias. La Comisión Investigadora fundó su trabajo en el Informe No 291/09 elaborado por la División Auditoría Administrativa Área Administración General y Defensa Nacional de la Contraloría General de la República, el que da cuenta del estado técnico, financiero y contable de los penales concesionados Grupos 1 y $3^{87}$. Ambos informes pasan revista a los principales hitos de la trayectoria del sistema de cárceles concesionadas, las dificultades en las que se vio envuelta y las irregularidades que la han aquejado y aquejan; y concluyen en un juicio implacable: el objetivo político del programa de concesiones desconoció las necesidades técnicas de su implementación y careció de una lectura global del problema carcelario.

Con todo, a inicios del año 2011, el gobierno de Sebastián Piñera anunció el desvío de la trayectoria de este modelo de concesiones, echando por tierra de manera intempestiva los proyectos contemplados en el plan de concesiones 2010-2014 ${ }^{88}$. Tras el desacierto

publicacionesyestudios/seminariosytalleres/Documents/sistema $\% 20$ penitenciario $\% 20$ concesionado_jorge $\% 20$ frei.pdf [Visitado por última vez el 22 de marzo de 2012].

${ }^{85}$ Decreto $\mathrm{N}^{\circ} 119$ del MOP de 17 de abril de 2010.

${ }^{86}$ Decreto $\mathrm{N}^{\circ} 90$ de 2004 del MOP de 02 de abril de 2004.

${ }^{87}$ Informe $\mathrm{N}^{\circ}$ 291/09 elaborado por la División Auditoria Administrativa Área Administración General y Defensa Nacional de la Contraloría de la República. Informe disponible en www.contraloria.cl. Cabe señalar que el documento no contempla el detalle de la operación del "Grupo 2". Ello se debería a que, a la época de su elaboración, se habría encontrado extinta dicha concesión.

88 A inicios de 2010 el Ministerio de Justicia y el MOP suscribieron un Segundo Programa de Concesiones de Infraestructura Penitenciaria, el cual contemplaba la construcción de cinco nuevos penales bajo la modalidad de concesión, ubicados en las ciudades de Calama, Copiapó, Valparaíso, Chillán y Temuco. 
de las concesiones carcelarias, el gobierno ha dado señales de reestructuración de su agenda penitenciaria, tornándose incierto el futuro de las alianzas público-privadas. En la página oficial del Ministerio de Justicia se anuncia que el gobierno contrató a la agencia norteamericana Altegrity Risk International para elaborar un estudio sobre la situación penitenciaria y un programa de propuestas. Al menos hasta la fecha de este trabajo, el informe fue denegado por los funcionarios competentes del Ministerio de Justicia, apelando al amparo otorgado por la causal de secreto prescrita en el artículo 21 numeral 3 de la Ley de Transparencia $N^{\circ} 20.285$, sosteniéndose que su divulgación podría poner en riesgo la seguridad pública ${ }^{89}$.

\section{CONCORDANCIAS}

El trasfondo político y económico que subyace al sistema de concesiones carcelarias en Chile ofrece semejanzas evidentes con el esquema privatizador de la experiencia internacional. En su faz económica, la experiencia chilena es vista como un particular ensayo neoliberal en la región llevado a cabo durante la dictadura de Pinochet y legitimado por los gobiernos de la Concertación de Partidos por la Democracia ${ }^{90}$. En su faz social, en Chile, como en otros países del llamado "segundo mundo", se han tolerado altos niveles de pobreza generalmente producto de la combinación entre una rápida liberalización económica y una restricción del Estado social ${ }^{91}$. Además, como en otros países de corte neoliberal, este entramado social y económico ha permitido que en Chile tengan lugar escandalosas cifras de encarcelamiento y violaciones de derechos humanos ${ }^{92}$. Felipe

Ya a fines del año 2010, los proyectos del "Grupo 4", que incluiría los complejos penitenciarios Talca y Santiago Dos, se encontraban en etapas de diseño y licitación. A la cuenta del 21 de mayo del año 2010, Sebastián Piñera afirmaba: "Respecto del Programa de Concesiones de Infraestructura Penitenciaria, se contará con diez establecimientos penitenciarios en operación, de los cuales cuatro se ejecutarán en este período, correspondiendo a una inversión total de aproximadamente 135 mil millones de pesos, en más de 165 mil metros cuadrados de construcción y otorgando más de seis mil 700 nuevas plazas. En total, las diez cárceles sumarán más de 16 mil 500 nuevas plazas al actual sistema penitenciario, cubriendo el 34 por ciento del total de población condenada e imputada". El discurso se encuentra disponible en http://www.injuv.gob.cl/ mensaje_presidencial/files/pdf/cuenta.pdf [Última visita realizada el 22 de marzo de 20120]. Un resumen de la evolución del programa puede encontrarse en la página de concesiones del gobierno. http://www. concesiones.cl/publicacionesyestudios/seminariosytalleres/Documents/Evolucion $\% 20$ Sistema $\% 20 \mathrm{de} \% 20$ Concesiones.pdf [Última visita realizada el 29 de marzo de 2012].

${ }^{89}$ El estado actual de las políticas penitenciarias y del debate surgido en torno a ellas, participa de una vertiginosa dinámica imposible de asir con exactitud. Las decisiones que en este momento se estén adoptando pueden revertir considerablemente la información que aquí se exponga, lo que justifica con mayor razón el interés por promover un debate que está aún lejos de agotarse.

${ }^{90}$ Harvey, op. cit., n. 32, p. 14.

${ }^{11}$ Wacquant, op. cit., n. 1. Passim.

92 Según el Informe de Derechos Humanos de la Universidad Diego Portales, el hacinamiento, la falta de condiciones mínimas de higiene dentro de los penales, los malos tratos de gendarmes a internos y el secretismo respecto de lo que sucede en los recintos penales son factores que agudizan y perpetúan la vulneración alevosa de los principios y derechos básicos contenidos en la normativa internacional de los 
Bulnes, ex Ministro de Justicia, en su exposición ante la Comisión de Constitución, Legislación y Justicia ${ }^{93}$ dio a conocer las estadísticas relativas a las condiciones carcelarias chilenas: afirmó que en Chile habría capacidad para albergar a 34.036 personas y una población penal recluida de aproximadamente 53.000 , alcanzando una tasa promedio de hacinamiento de $60 \%{ }^{94}$.

El fenómeno de explosión carcelaria es, además, parte de una inquietante cultura de la penalidad, en la cual se desenvuelven nuevos agentes -víctimas y medios de comunicación-, nuevos equilibrios -la participación de los privados en la provisión de su seguridad-, nuevos mecanismos de solución de conflictos -la justicia penal negociada-, nuevas organizaciones - grupos intermedios orientados a la prevención del delito-, nuevas políticas -la justicia expresiva y el populismo punitivo-, nuevas audiencias -la sociedad civil en constante alerta-, y nuevas formas de provisión de servicios -los contratos de concesión penitenciaria ${ }^{95}$.

Además, y tal como en la experiencia comparada, el discurso público en Chile legitima con una retórica efectista el fortalecimiento de la capacidad del brazo penal del Estado y la intervención del sector privado en el aparato carcelario. En el mensaje presidencial del año 2001, por ejemplo, Ricardo Lagos incluyó la promesa de construcción de diez nuevas unidades penales, buscando duplicar la superficie carcelaria y afirmando ser la "única forma que tenemos de abordar a plenitud este tema" ${ }^{96}$. Las cifras físicas del proyecto de concesiones carcelarias fueron reiteradas hasta la saciedad: 10 nuevas cárceles, una inversión cercana a los 280 millones de dólares y la construcción de 372 mil metros cuadrados para alojar a alrededor de 16.000 reclusos ${ }^{97}$. Como puede

derechos humanos. Centro de Derechos Humanos Universidad Diego Portales, Informe Anual sobre Derechos Humanos en Chile 2010. Santiago, Ediciones Universidad Diego Portales, 2010, p. 110. Todos los informes se encuentran disponibles en http://www.derechoshumanos.udp.cl/archivo/informe-anual/ [Visitado por última vez el 30 de marzo de 2012].

93 Acta de la Comisión de Constitución, Legislación y Justicia. $358^{a}$ Legislatura. Sesión $57^{\text {a }}$ Ordinaria de 21 de diciembre de 2010, p. 7 y siguientes.

${ }^{94}$ Bulnes también aseveró que existirían en Chile niveles de encarcelamiento particularmente elevados, alcanzando una tasa de 317 personas por cada 100.000 habitantes, situándose entre los países con más altas tasas de encarcelamiento en la región.

95 Esta conjunción de fenómenos ha sido abordada por los trabajos de David Garland, considerado el mayor referente en el estudio del nexo entre delito y orden social después de los escritos de Michel Foucault.

${ }^{96}$ Nótese que el día anterior al discurso del 21 de mayo, la cárcel de Iquique era objeto de un incendio de proporciones. En la tragedia murieron 26 internos y 140 quedaron heridos. Luego de ella, el Ministro de Justicia de la época José Antonio Gómez, anunció la construcción de diez cárceles concesionadas. Información de la prensa disponible en "Nuevo incendio en cárcel de Iquique”. Diario El Mercurio, Santiago, 22 de mayo de 2011. Disponible en http://www.emol.com/noticias/nacional/2001/05/22/55505/nuevo-incendio-encarcel-de-iquique.html [Visitado por última vez el 29 de marzo de 2012].

${ }^{97}$ Entre otros, Arellano, op. cit., n. 28, p. 11. Dammert, L. "El sistema penitenciario en Chile: Desafíos para un modelo público-privado", En Meeting of the Latin American Studies Association, 2006 San Juan, Puerto Rico, p. 10. Disponible en http://www.flacso.cl/home/images/extension/congreso/lasa2006-sistemapenitenciario.pdf [Visitado por última vez el 29 de marzo de 2012]. Centro de Derechos Humanos Universidad Diego Portales, Informe Anual sobre Derechos Humanos en Chile 2006. Santiago, Ediciones Universidad Diego Portales, 2006, pp. 35-36. 
confirmarse, tal como en otros países, la finalidad expansiva del Estado penal chileno confió en el sector privado para desarrollar un mercado en potencial sincronía con el poder de castigar, lo que ilustra con propiedad los efectos de una economía de libre mercado asociada a la expansión del brazo punitivo estatal. Ahora bien, aun cuando la versión chilena de privatización carcelaria adoptó un modelo privatizador mixto, con una participación fragmentada del sector privado, ha de estimarse ser coherente con la desbocada carrera de los gobiernos neoliberales por resistir con su mano punitiva los estragos de la amputación de su mano social.

En un breve acercamiento a los resultados de la experiencia privatizadora, luego de la revisión de estudios comparativos dedicados a investigar si el sector privado consigue mejorar la calidad del servicio proveído por el sector público, tanto en Chile como en Estados Unidos los estudios demuestran que los servicios proveídos por ambos tipos de instalación son de calidad similar ${ }^{98}$. Sumado a ello, ni en Chile ni en Estados Unidos la gestión del sector privado da cuenta de cifras positivas en términos de superar las probabilidades de reinserción en contraste con el sector público 99.

En definitiva, Chile, de manera paulatina, impulsa la hipertrofia del Estado penal, instándolo a reforzar su intervención en el terreno carcelario. El problema es que la participación de capitales privados en el sistema penitenciario levanta un velo de sospecha del cual las autoridades no se han hecho cargo, desconociendo además que la herramienta penal es incapaz de resolver las profundas divisiones sociales desatadas por el neoliberalismo.

98 Pratt y Maahs concluyen que la propiedad de la instalación (pública o privada) es un predictor insignificante en la medida estandarizada de costo diario por preso. Pratt, T. y Maahs, J. op. cit., n. 1. Lundhal, al evaluar diez distintos indicadores de calidad, como costos, seguridad pública, seguridad interna, orden, atención médica, capacitación, beneficios, reclamos por parte de los presos, condiciones de la instalación y clima laboral, señala que existiría una calidad similar entre aquella proveída por el sistema público y la proveída por el sector privado. Lundahl, B. et al. "Prison Privatization: A Meta-analysis of Cost and Quality of Confinement Indicators", en Research on Social Work Practice, Vol. 19 N $^{\circ} 4$, 2009. En cuanto al caso chileno, el Programa de Concesiones trajo consigo servicios antes inexistentes e importantes medidas de mejoramiento que dan cuenta de un indudable avance, pero persisten falencias estructurales, como las deficiencias en infraestructura, la irregularidad en la atención médica y la dudosa calidad de los servicios de alimentación.

${ }^{99}$ Bales, W. et al. "Recividivim of Public and Private State Prison Inmates in Florida", en Criminology and Public Policy, Vol. $4 \mathrm{~N}^{\circ}$ 1. 2005. Bales y su equipo concluyen que en la medida en que los operadores privados estén cumpliendo con la expectativa de reinserción es una incógnita cuya resolución requiere generar documentación fiable y convincente de la cual se carece actualmente. Similar situación delatan Olga Espinoza y Fernando Martínez respecto de la situación chilena, quienes afirman que a más de carecerse de evaluaciones objetivas, la escasa información disponible delata numerosas deficiencias, las que van desde la irregularidad en la confección de fichas técnicas por preso, la falta de espacio, la ausencia de datos fiables y sucesivas infracciones en la asistencia e impartición de talleres. Martínez, F. y Espinoza, O. "Cárceles concesionadas en Chile: ¿El camino a la privatización?”, en Debates Penitenciarios Nº 9, 2009. 


\section{BIBLIOGRAFÍA}

ACta de la Comisión de Constitución Legislación y Justicia, $358^{a}$ Legislatura. Sesión $57^{\mathrm{a}}$ Ordinaria de 21 de diciembre de 2010.

Aman, Alfred, "Privatization, prisons, democracy, and human rights: The need to extend the province of administrative law", Indiana Law, Vol. 33, pp. 511-550. 2005. Legal Studies Research Paper Series.

Arellano, Jaime, "Reforma Penitenciaria: El caso del programa de concesiones en infraestructura penitenciaria en Chile". En: Seminario Justicia y Gobernabilidad Democrática del Centro de Estudios de Justicia de las Américas y Ministerio de Justicia de Chile, 2003, Santiago de Chile.

Austin, James y Coventry, Gary, "Emerging Issues on Privatized Prisons”. U.S Department of Justice, 2001.

Bales, William, Bedard, Laura, Quinn, Susan, Ensley, David, Holley, Glen, "Recividivim of Public and Private State Prison Inmates in Florida". Criminology and Public Policy, Vol. 4 $\mathrm{N}^{\circ} 1$, pp. 57-82. 2005.

Braithwaite, John, Regulatory Capitalism: How it Works, Ideas for Making it work Better. Edward Elgar Publishing, Londres, 2008.

Centro de Derechos Humanos Universidad Diego Portales, Informe Anual sobre Derechos Humanos en Chile 2010. Santiago, Ediciones Universidad Diego Portales, 2010.

Centro de Derechos Humanos Universidad Diego Portales, Informe Anual sobre Derechos Humanos en Chile 2006. Santiago, Ediciones Universidad Diego Portales, 2006.

Centro de Estudios Jurídicos y Formación Especializada, “¿Políticas del castigo? Análisis comparativo del discurso de política penitenciaria en: Dinamarca, Francia, Inglaterra, Gales y Canadá”, Generalitat de Catalunya. Departamento de Justicia, Barcelona, 2009.

Comisión Episcopal de Acción Social, Perú: Informe sobre la situación penitenciaria. CEAS, Lima, 2005.

Dammert, Lucía, "El sistema penitenciario en Chile: Desafíos para un modelo público-privado", En Meeting of the Latin American Studies Association, 2006 San Juan, Puerto Rico.

Dana, Joel, A Guide to Prison Privatization, Washington, Heritage Foundation Backgrounder,1988.

Del Rosal, Bernardo, “La 'privatización' de las prisiones: una huida hacia la pena de privación de libertad”, Eguzkilore: Cuaderno del Instituto Vasco de Criminología, Vol. 12, 1998, pp. 115-132.

Diario de los Debates de la Cámara de Diputados, Sesión del 23 de noviembre de 2010.

Diario El MerCuRIo, "Nuevo incendio en cárcel de Iquique". Santiago, 22 de mayo de 2011.

Dolovich, Sharon, "State punishment and private prisons". Duke Law Journal, Vol. $55 \mathrm{~N}^{\circ} 3$, 2005 , pp. 437-546.

Espinoza, Olga y Martínez, Fernando, "Cárceles concesionadas en Chile: ¿El camino a la privatización?”. Debates Penitenciarios No 9, 2009, pp. 3-15.

Figueroa, Juan Eduardo, "El arbitraje en los contratos de concesión de obras públicas en Chile. Incorporación de los Dispute Boards o Paneles Técnicos o de Expertos”, en Gaceta Jurídica $\mathrm{N}^{\circ} 350,2009$, pp. 7-16.

Foucault, Michel, Vigilar y Castigar: el Nacimiento de la prisión, Siglo Veintiuno Editores, Madrid, 2000.

Frei, Jorge, "Seminario regional. Sistema penitenciario concesionado: desafíos y realidades regionales". Rancagua, Gobierno de Chile-Ministerio de Justicia, 2009.

Frey, Antonio, "Seguridad ciudadana, ambivalencia de las políticas criminológicas y privatización del sistema carcelario", en Revista de la Academia No 5, 2000. 
GARLAND, David, La cultura del control. Crimen y orden social en la sociedad contemporánea, Gedisa, Barcelona, 2005.

Ghersi, Enrique, "El mito del neoliberalismo”. Estudios Públicos No 95, 2004, pp. 293-313.

Harcourt, Bernard, The Illusion of Free Markets: Punishment and the Myth of Natural Order, Harvard University Press, Cambridge, 2011.

Harvey, David, Breve historia del neoliberalismo, Ediciones Akal, Madrid, 2007.

Informe de la Comisión Especial Investigadora sobre el Proceso de Concesiones Carcelarias (2008). El informe fue presentado ante la Cámara de Diputados en la $356^{a}$ Legislatura. Sesión 116 ${ }^{a}$ Ordinaria de 16 de diciembre de 2008.

Informe N 291/09. División Auditoría Administrativa Área Administración General y Defensa Nacional de la Contraloría General de la República.

InSTITUCión PEnitenCiaRia, "El sistema penitenciario español”. Secretaría general de instituciones penitenciarias, Madrid, 2011, p. 37.

Logan, Charles, Private Prisons. Cons E Pros, Oxford University Press, New York, 1990.

Lundahl, Brad, Kunz, Chelsea, Brownell, Cyndi, Harris, Norma, Van Vleet, Ruzz, "Prison Privatization: A Meta-analysis of Cost and Quality of Confinement Indicators", en Research on Social Work Practic, Vol. 19 No 4, 2009, pp. 383-394.

McDonald, Douglas, "Public Imprisonment by private means: The re-emergence of private prisons and jails in the United Stated, the United Kingdom and Australia", en British Journal of Criminology, Vol. $34 \mathrm{~N}^{\circ} 29,1994$, pp. 29-48.

Ministerio Del INTERIOR DE EsPaÑa, "Interior invertirá más de 1.647 millones de euros en la construcción de 46 nuevas infraestructuras penitenciarias”. 18 de noviembre de 2005.

Parenti, Christian, Lockdown America: Police and Prisons in the Age of Crisis, Editorial Verso, New York, 2000.

Pratt, Travis, Maahs, Jeff, "Are Private Prisons More Cost-Effective Than Public Prisons? A Meta-Analysis of Evaluation Research”, en Crime and delinquency, Vol. 45 No 3, 1999, pp. 358-372.

Ruiz-Jarabo, DÁmaso, "Prisiones privadas", Jueces para la democracia. Información y Debate. $\mathrm{N}^{\circ} 8$, 1989, pp. 40-46.

SANZ, EnRIQUe, "Los límites de la participación privada en el ámbito penitenciario", en Anuario de Derecho Penal y Ciencias Penales, Vol. 52 N 1-3, 1999.

SANZ, ENRIQUe, Las prisiones privadas: la participación privada en la ejecución penitenciaria. Madrid, Edisofer, 2000.

SCHICHOR, DAvid, "Private prisons in perspective: some conceptual issues", en The Howard Journal, Vol. 37 No 1, 1998, pp. 82-100.

Schlosser, Eric, The Prison-Industrial Complex, Atlantic Monthly, 1998.

SMINC, VerónicA, "Brasil tendrá las primeras cárceles privadas en América Latina”. BBC Mundo Cono Sur. Domingo, 19 de junio de 2011.

Tapia, Fabiola, Hacia la Privatización de las Prisiones, Editorial Ubijus, México DF., 2011.

WaCQuAnt, Loïc, Las cárceles de la miseria, Buenos Aires, Ediciones Manantial, 2000.

Wacquant, Loïc, Castigar a los pobres: El gobierno neoliberal de la inseguridad social, Gedisa, Barcelona, 2010.

WACQUANT, LoÏc, "El cuerpo, el gueto y el Estado penal", en Apuntes de investigación $\mathrm{N}^{\circ}$ 16/17. 2010, pp. 113-145.

Weiss, Robert, "Repatriating Low-Wage Work: The Political Economy of Prison Labor Reprivatization in the Postindustrial United States", en Criminology, Vol. 39 N $^{\circ} 2$, 2011, pp. 253-292. 
Western, Bruce, "The impact of incarceration on wage mobility and inequality", en American Sociological Review, Vol. 67, agosto, 2002, pp. 526-546.

White, Ahmed, "Rule of law and the limits of sovereignty: the private prison in jurisprudential perspective", en The American Criminal Law Review, Vol. 38 N 1, 2001, pp. 111-146. Williamson, Bernardita, "Los modelos de administración de centros privativos de libertad". En: Fundación Paz Ciudadana, Estudio sobre Modelos de Intervención y Administración de Centros Privativos de Libertad en la Reforma Penal Adolescente. Informe Final. Santiago, Ministerio de Justicia, 2009, pp. 37-44. 
